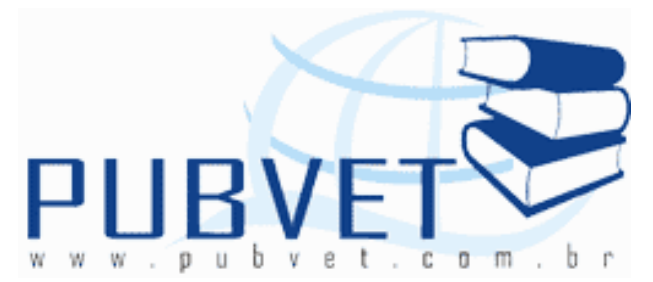

PUBVET, Publicações em Medicina Veterinária e Zootecnia.

\title{
Estação de monta de um rebanho nelore no Estado de Goiás
}

Gabriela Lucia Bonato ${ }^{1}$ e Ricarda Maria dos Santos ${ }^{2}$

1 Graduada e mestranda pela Universidade Federal de Uberlândia

2 Professora doutora titular da Faculdade de Medicina Veterinária da Universidade Federal de Uberlândia.

\section{Resumo}

Objetivou-se com este trabalho apresentar as taxas de prenhez de categorias animais diferentes do primeiro ano de uma estação de monta realizada no estado de Goiás, bem como ressaltar a importância dessa prática tão simples, mas que proporciona ganhos tanto produtivos quanto financeiros para o produtor. O rebanho era composto por 334 matrizes, das quais 48 eram novilhas, 123 primíparas e 163 multíparas. A estação de monta compreendeu os meses de dezembro de 2010 a abril de 2011, sendo que as novilhas entraram com 15 dias de antecedência em relação ao restante do rebanho e a proporção de touros/vaca foi 1:30. O diagnóstico de prenhez foi feito por meio de ultrassonografia 45 dias após o final da estação. A taxa de prenhez foi de $79,1 \%, 51,2 \%$ e $67,4 \%$ respectivamente para novilhas, primíparas e multíparas, revelando a dificuldade das primíparas para se adequarem à estação de cobertura.

Palavras-chave: gado de corte, taxa de prenhez, bezerros. 
BONATO, G.L. e SANTOS, R.M. Estação de monta de um rebanho nelore no Estado de Goiás.

PUBVET, Londrina, V. 5, N. 34, Ed. 181, Art. 1218, 2011.

\title{
Breeding Season of a Nelore cattle in Goiás state
}

\begin{abstract}
The objective of this work to present rates of pregnant animals different categories of the first year of a breeding season held in the state of Goias, and to underscore the importance of this practice so simple, but provides both productive and financial gains for the producer. The herd consisted of 334 arrays, 48 of which were heifers, 123 primiparous and 163 multiparous. The breeding season lasts from December 2010 to April 2011, and the heifers filed 15 days in advance of the rest of the herd and the proportion of bull / cow was $1: 30$. The pregnancy diagnosis was made by ultrasound 45 days after the end of the season. The pregnancy rate was $79.1 \%, 51.2 \%$ and $67.4 \%$ respectively for heifers, primiparous and multiparous, revealing the difficulty of first births to suit the breeding season.
\end{abstract}

Keywords: beef cattle, pregnancy rate, calf.

\section{Introdução}

O sistema de cria no Brasil passa por momentos de reconhecimento sobre a importância da eficiência reprodutiva, visando aumento dos lucros por meio de mais bezerros desmamados anualmente e redução de custos com descarte de vacas improdutivas.

A reprodução assistida implementada através de simples estratégias de manejo que promovam a ocorrência de eventos em momentos préestabelecidos, como a época de cobertura de matrizes e conseqüentemente de nascimentos de bezerros, constitui uma ferramenta eficaz para melhorar a produtividade do sistema (PENTEADO et al., 2005).

Segundo Torres-Júnior e colaboradores (2009), devido a extensão territorial do Brasil, cada região do país realiza a estação de monta em 
BONATO, G.L. e SANTOS, R.M. Estação de monta de um rebanho nelore no Estado de Goiás. PUBVET, Londrina, V. 5, N. 34, Ed. 181, Art. 1218, 2011.

determinada época do ano, isso porque é o regime de chuvas, ou seja, período seco ou chuvoso que representa os momentos mais marcantes para o setor agropecuário. Dentro dessa variação anual, a disponibilidade de forragem direciona a época mais adequada às atividades de monta, nascimentos e desmame. O déficit nutricional pode prejudicar substancialmente 0 desenvolvimento dos bezerros e a fertilidade das fêmeas, prolongando o intervalo de partos devido ao aumento do período de serviço (intervalo partoconcepção).

Geralmente a estação de monta se inicia com as primeiras chuvas, quando ocorre a rebrota dos pastos e conseqüentemente há um maior número de fêmeas apresentando cio (VALLE, ANDREOTTI, THIAGO, 2000). No caso da região central de Goiás, este período ocorre entre novembro e fevereiro. Dessa forma, os nascimentos ocorrem entre agosto e outubro (período seco), ideal pela baixa infestação de parasitas. O desmame geralmente realizado aos 7 meses, ocorre entre março e maio, época que apresenta boa oferta de forragens, essencial ao desenvolvimento dos bezerros, além da uniformização dos lotes e recuperação da condição corporal das matrizes.

Objetivou-se com este estudo calcular e comparar as taxas de prenhez das seguintes categorias animais: novilhas, primíparas e multíparas no primeiro ano (implantação) de uma estação de monta no estado de Goiás.

\section{Material e Métodos}

A estação de monta foi realizada numa propriedade no município de Ipameri, estado de Goiás. Participaram da estação 334 fêmeas bovinas Nelore, das quais 48 eram novilhas, 123 primíparas e 163 multíparas. A estação compreendeu os meses de dezembro de 2010 a abril de 2011.

As novilhas que foram selecionadas para a estação tiveram peso vivo acima de $290 \mathrm{Kg}$ e ingressaram 15 dias de antecedência em relação às vacas com o propósito de parirem primeiro e terem mais tempo para recuperarem a condição corporal a fim de facilitar a concepção na estação seguinte. 
BONATO, G.L. e SANTOS, R.M. Estação de monta de um rebanho nelore no Estado de Goiás. PUBVET, Londrina, V. 5, N. 34, Ed. 181, Art. 1218, 2011.

Os touros utilizados nas coberturas foram da raça Nelore e distribuídos na proporção de 1:30, ou seja, um touro para cada 30 fêmeas.

O diagnóstico de gestação foi realizado por meio de ultrassonografia, aparelho Mindray DP3300®, aos 45 dias após o término da estação.

\section{Resultados e Discussão}

A taxa de prenhez das novilhas foi de 79,1\% (38/48), ou seja, grande parte dessas novilhas emprenharam porque já estavam em idade reprodutiva e apresentaram uma boa condição corporal, visto que, a seleção das mesmas teve como critério o peso vivo. Esse índice se aproxima do encontrado por Jorge Júnior et al. (2006), que relataram uma taxa de prenhez média de $85,0 \%$ para novilhas da raça Nelore, porém utilizando inseminação artificial numa estação de 90 dias.

A taxa de prenhez das primíparas foi de $51,2 \%$ (63/123), bem inferior à das novilhas, pois é a categoria animal que mais necessita de atenção. A primípara além dispor energia com mantença, crescimento, reprodução, ela ainda gasta com a lactação, daí a dificuldade de enfrentar um período curto de recuperação e logo já se tornar prenhe na próxima estação. Conforme foi realizado nesta pesquisa, o ideal é colocá-las na estação antes das vacas para que tenham mais tempo para recuperação até chegar a estação seguinte. Nossos dados se aproximam da taxa de prenhez em primíparas de $43 \%$ encontrada por Batista e Abreu (2010).

Dias (1991) trabalhou com vacas de corte zebuínas e concluiu que o escore de condição corporal está altamente relacionado com a duração da estação reprodutiva, pois quanto menor for este fator, maior é o intervalo entre o parto e a concepção. Daí a dificuldade de reduzir a duração da estação de monta a cada ano.

Já a Taxa de prenhez das multíparas foi de $67,4 \%$ (110/163), o que se espera de um primeiro ano de estação de monta. A implantação da técnica 
BONATO, G.L. e SANTOS, R.M. Estação de monta de um rebanho nelore no Estado de Goiás. PUBVET, Londrina, V. 5, N. 34, Ed. 181, Art. 1218, 2011.

abrange animais em diferentes estágios de gestação e assim muitas fêmeas não conseguem emprenhar durante o período pré-estabelecido e aguardam a próxima estação. Marques et al. (2005) realizaram um trabalho com multíparas Nelore com suplementação ou não de seus bezerros e encontraram uma taxa de prenhez de $93 \%$ e $84 \%$ respectivamente, portanto em estação já estabelecida. Essa diferença é explicada pela menor intensidade de amamentação no grupo de bezerros suplementados, já que a amamentação influencia negativamente a reprodução.

Nos próximos anos, a tendência do rebanho do presente estudo é o encaixe de todas as fêmeas no mesmo período de cobertura.

\section{Conclusão}

A implantação de uma estação de monta, apesar de simples, requer alguns critérios e cuidados no manejo para encurtar cada vez mais o período de cobertura.

\section{Referências}

BATISTA, D. S. N.; ABREU, U. G. P. Alguns Aspectos da Eficiência Reprodutiva no Rebanho Nelore da Estação Experimental do Pantanal. In: SIMPÓSIO SOBRE RECURSOS NATURAIS E SOCIOECONÔMICOS DO PANTANAL, 5., 2010, Corumbá MS. Disponível em:

http://www.alice.cnptia.embrapa.br/bitstream/doc/868177/1/sp17239.pdf. Acesso em: 24 jul. 2011.

DIAS, F.M.G.N., Efeito da condição corporal, razão peso/altura e peso vivo sobre o desempenho reprodutivo pós-parto de vacas de cortes zebuínas. Belo Horizonte, MG. Escola de Veterinária, 1991. 100p. Dissertação (Mestrado em Zootecnia) - Universidade Federal de Minas Gerais, 1991.

JORGE JÚNIOR, J.; CARDOSO, V. L.; ALBUQUERQUE, L. G. de. Modelo bioeconômico para cálculo de custos e receitas em sistemas de produção de gado de corte visando à obtenção de valores econômicos de características produtivas e reprodutivas. Revista Brasileira de Zootecnia, Viçosa, v.35, p.2187-2196, 2006.

MARQUES, J. A.; ZAWADZKI, F.; CALDAS NETO, S. F.; GROFF, A. M.; PRADO, I. N.; SILVA, R. E. Efeitos da suplementação alimentar de bezerros mestiços sobre o peso à desmama e taxa de prenhez de vacas multíparas Nelore. Archivos latinoamericanos de produccion animal, Mayaguez, v.13, n.3, p.92-96, 2005. 
PENTEADO, L. et al. Eficiência reprodutiva em vacas nelore (bos indicus) lactantes submetidas a diferentes manejos durante a estação de monta. In: CONGRESSO BRASILEIRO DE REPRODUÇÃO ANIMAL, 16. 2005, Goiânia. Anais... Belo Horizonte: Colégio Brasileiro de Reprodução Animal, 2005. p. 271.

TORRES-JÚNIOR, J. R. S.; MELO, W. O.; ELIAS, A. K. S. et al. Considerações técnicas e econômicas sobre reprodução assistida em gado de corte. Revista Brasileira de Reprodução Animal, Belo Horizonte, v.33, n.1, p.53-58, 2009. Disponível em: http://<www.cbra.org.br>. Acesso em: 13 jun 2011.

VALLE, E. R.; ANDREOTTI, R.; THIAGO, L. R. L. S. Técnicas de manejo reprodutivo em bovinos de corte. Campo Grande, MS: Embrapa Gado de Corte, 2000. 61p. 